\title{
Electronic Aids to Emotional Relations: A Mind Genomics Development Cartography of a 'Dating App'
}

\author{
Konstantin Vuk Savicevich¹, Janna Kaminsky², Martin Braun², Attila Gere ${ }^{3}$, Sharon Starke ${ }^{4}$ and Howard Moskowitz ${ }^{*}$
}

${ }^{1}$ Tino Space, Belgrade, Serbia

${ }^{2}$ Queens College, City University of New York, NY, USA

${ }^{3}$ Szent Istvan University, Budapest, Hungary

${ }^{4}$ Starke Solutions LLC, Miami, Florida, USA

${ }^{5}$ Mind Genomics Associates, Inc. White Plains, NY, USA

${ }^{*}$ Corresponding Author: Howard Moskowitz, Mind Genomics Associates, Inc. USA and Mind Genomics Center of Excellence, Szent Istvan University, Budapest, Hungary; Email: mjihrm@sprynet.com

Received: August 20, 2019; Accepted: August 28, 2019; Published: September 29, 2019;

\begin{abstract}
We present a new approach to understand what draws individuals to romantic 'dating' sites. The approach follows a Socratic sequence, requiring the researcher to follow a set of steps. These begin with defining the topic (dating site), then ask six related questions which 'flesh out' the topic, and then require six answers for each question, these answers or elements providing the detail. The actual approach is an experiment, in which test participants (respondents) evaluated 48 different combinations of these answers, in short vignettes comprising $2-4$ answers. The relation between the individual respondent's ratings and the presence/absence of the 36 elements allow for a regression model, whose parameters show the contribution of the elements. The process creates a database of knowledge (what do people want), identifies complementary mind-sets, and then creates a personal viewpoint identifier (PVI) which assigns a new person to one of the mind-sets by a simpler set of six questions, and one of two possible answers. We discuss the potential of this simple, rapid, cost-effective, and powerful method to create a large library about the 'mind of the consumer.'
\end{abstract}

\section{Introduction}

A great deal of the popular press, especially on the Internet, involves the search for relationships, especially between those who would be called 'potential partners.' A quick look at 'relationship dating apps' in Google comes up with 366 MILLION 'hits', 'dating sites' comes up with 704 MILLION hits. Asking for the 'best'dating apps' produces a long list, some which are: Zoosk ${ }^{\circledR}$, Match $^{\oplus}$, Elite ${ }^{\oplus}$, Silver Singles ${ }^{\circledR}$, and so forth. Moving over to the academic world, with Google Scholar, the repository of academic publications, we see 1.4 MILLION hits for 'dating sites' and 33,200 hits for 'dating apps.'

Of course, we do not have to go to Google ${ }^{\circledast}$ or the scientific literature. We need only listen to the casual conversations around us to know how focused people are on their current partners, past partners, possible partners, and of course the world of non-partners considered from the viewpoint of casual relationships.

To capitalize on this search for partners and this fascination, a variety of companies have been formed to match partners. The applications do not begin as of this writing, or even as of this century, but go back to the 1960's with computer dating. Indeed, author Moskowitz has had personal experience with these programs as far back as 1966, when the computer was recognized as a device to 'match profiles',

The presumed superiority of on-line dating sites comes from claiming that an underlying algorithm is better at matching two people than the traditional methods, such as blind introduction by friends of relatives. Whether, in fact, the algorithm is better than judgment is not the topic of this study. Rather, it would appear that even if the algorithm were not as good as judgment, the dating site comes up with an assortment of prospective partners, making the pursuit of the 'right partner' more time-efficient [1] There are a variety of studies of the user of the dating site from different aspects of the person himself or herself [2-6] but these studies do not appear to focus on the dating site as a product to be created, like any other consumer product.

\section{Background}

We use the emerging science of Mind Genomics to understand how people respond to the features of an online dating 'app.' Mind Genomics is an emerging psychological science dealing with the experimental analysis of the 'everyday', and, specifically, the criteria by which we make decisions $[7,8]$ Mind Genomics is an 'experimenting science,' which means it bases its data on the results of experiments in which the respondents are given various combinations of messages, features, ideas, combined in assortments according to a plan, so-called experimental design [9] The objective is to estimate how every one of the different messages of features 'drives' a response, whether the response be interest (our first rating question), or selection of a feeling after reading the combination.

The notion of experiment is important in Mind Genomics. A great deal of information about people, about desires in relationships, and 
so forth, is obtained by direct questions, the survey procedure. The survey answers are tabulated, analyzed through statistics, perhaps correlated with each other and with outside information, until the answers emerge through a pattern. The survey may be attitudinal. Another approach, increasingly popular, observe behavior in a natural setting, such as search information, and establishes patterns from the search information.

Mind Genomics is neither a survey of attitudes and practices, nor an observation of free ranging behavior in a choice situation. Rather, Mind Genomics is an experiment. Mind Genomics presents the ideas in combinations, vignettes, as noted above, deconstructs the response into the contribution of the individual components of the combination, the vignette, and then identifies a pattern from the data. The components, i.e., phrases, are 'cognitively rich.' They are statements about behavior which can stand alone and have meaning, the type of information to which we would ordinarily be subjected. It becomes easy to discover new ideas by simply looking at the 'meaning' of elements which perform well together in a specific subgroup.

\section{Putting the Mind Genomics approach into action with 'Online Dating'}

The study comes from the interest of the authors in the nature of relationships, and what people want from a technology which creates the introduction. The topic, while not seeming profound, is actually quite deep in terms of the engagement of people who 'set up the study' That is, for many Mind Genomics studies the efforts to create the study are made, but there is little excitement at the beginning. The topics may be profound, but to the ordinary person, the non-expert, the topics are mundane, if not downright boring. In contrast, the group(s) working on this study and similar studies comprised mainly women, typically between the ages of 18 and 50, rather than men. The topic, the questions, the answers (elements), were generated by women.

Step 1: Choose the topic and ask six questions which 'tell a story.' The topic as chosen was 'online dating', specifically the features that a person would find interesting, and the emotions that would be experienced when using this online dating. Table 1 presents the six questions, and for each question, six answers.

\section{Combining Elements (Answers To The Questions) Into An Experimental Design}

One of the tenets of Mind Genomics is that people cannot easily tell the researcher 'what is important' or, in a more quantitative fashion, assign the level of importance of each aspect of a situation. We may believe we can, but our judgment of what we read, what we see, what we hear, feel, smell and taste is so rapid that it is likely that any post-hoc reporting of what was important for the judgment may be a rationalization, an intellectualization of an otherwise rapid, almost automatic process. Indeed, Nobel Laureate Daniel Kahneman suggests that most of our everyday decisions come from an automatic reaction to the situations which confront us, decisions that are controlled by so-called System 1. When we are asked to think in a rational way, even about what has been reacted to automatically, we invoke a slower system, so-called System 2 [10]
Table 1. The six questions and the six answers to each question

\begin{tabular}{|c|c|}
\hline & Question A: How does it work, and what does it do? \\
\hline A1 & Easy login... with Facebook \\
\hline $\mathbf{A 2}$ & Online dating made easy \\
\hline $\mathbf{A 3}$ & Meet singles all around the world \\
\hline A4 & Registration is fast and effortless \\
\hline A5 & Fast efficient match making tools \\
\hline \multirow[t]{2}{*}{ A6 } & Receive matches by e-mail, free \\
\hline & Question B: How do numbers prove your point? \\
\hline B1 & We are the best predictors of happy and long-lasting relationships \\
\hline B2 & $\begin{array}{l}\text { Has more dates, more relationships and more visits than any other online } \\
\text { dating website }\end{array}$ \\
\hline B3 & Over 1 million conversations per day, with 30,000 new singles everyday \\
\hline B4 & Over 8,000 singles online now...making more connections everyday \\
\hline B5 & $\begin{array}{l}\text { Debbie from New York says, "I never thought I would use a dating website... } \\
\text { but that is how I met my husband, Paul" }\end{array}$ \\
\hline \multirow[t]{2}{*}{ B6 } & In the USA, 1 out of every couple found their spouse online \\
\hline & $\begin{array}{l}\text { Question C: How do you appeal to authority, and what kind of tag lines } \\
\text { support your appeal? }\end{array}$ \\
\hline C1 & Date smarter, not harder \\
\hline $\mathrm{C2}$ & $\begin{array}{l}\text { One-of-a-kind questionnaire to dig deeper to uncover your attitudes, beliefs } \\
\text { and personality }\end{array}$ \\
\hline $\mathbf{C 3}$ & Find G-d's match for you \\
\hline $\mathrm{C} 4$ & A fun, unique way to meet people \\
\hline C5 & Start finding all of the Mr. and Ms' Rights you can handle \\
\hline \multirow[t]{2}{*}{ C6 } & $\begin{array}{l}\text { Our online dating site and dating service is modern, professional and user- } \\
\text { friendly }\end{array}$ \\
\hline & Question D: How do you ensure technical security? \\
\hline D1 & Number one most trusted online dating website \\
\hline D2 & $100 \%$ invitation only...to better protect your privacy \\
\hline D3 & $\begin{array}{l}\text { Your information is stored in our database for historical and legal purposes } \\
\text { only }\end{array}$ \\
\hline D4 & Make yourself invisible with our one-of-a-kind privacy settings \\
\hline D5 & $\begin{array}{l}\text { For singles concerned with privacy, rest assured contact details are never } \\
\text { published }\end{array}$ \\
\hline \multirow[t]{2}{*}{ D6 } & Ranked in 2011 as McAfee's most secure dating website \\
\hline & Question E: What are 'simple' reason to believe \\
\hline E1 & Oldest online dating website \\
\hline E2 & Use our respectable matching system \\
\hline $\mathbf{E 3}$ & Personal match maker working with you \\
\hline $\mathbf{E 4}$ & Partnership with Match.com to increase our services to you \\
\hline E5 & $\begin{array}{l}\text { No other website offers relationship expertise of someone like Dr. Phil or } \\
\text { professional match making services }\end{array}$ \\
\hline \multirow[t]{2}{*}{ E6 } & Our website gives more meaning to 'we are family' than any other \\
\hline & Question F: What are the fees? \\
\hline F1 & Free personality test...matches you with more singles in your area \\
\hline F2 & Online dating for the cost of a single date \\
\hline F3 & Free trial for your first three months \\
\hline F4 & No credit card required \\
\hline F5 & Pay as you go...no contract necessary \\
\hline F6 & Put away your credit card...everything on this website is free \\
\hline
\end{tabular}


Mind Genomics works using experimental design, which combines the elements into vignettes, test combinations, with the property that each vignette comprises a limited number of elements (2-4), with at most one element or answer from a question. The rationale is that the experimental design is useful both for ensuring the downstream statistical analyses by regression, and a bookkeeping device to prevent the juxtaposition of potentially mutually contradictory pieces of information in one vignette.

Each respondent evaluated a set of 48 vignettes, with each respondent evaluating a set of combinations totally different from the combinations evaluated by another respondent. The structure of the underlying experimental design is maintained. The mathematics allows the elements to appear an equal number of times, and ensures that at the level of an individual respondent the 36 elements are statistically independent of each other.

The use of mixtures, and the measurement of subjective response to those mixtures, constitutes a hallmark of Mind Genomics. The research strategy focuses on the response of a respondent to a series of unique combinations, with no discernable pattern, no single 'story', and therefore an array of test stimuli, which in the words of psychologist
William James, constitute a 'blooming, buzzing confusion. One cannot 'game' this system. The stimuli come quickly, change, demanding simply that the respondent react to the combinations, a response which may start out as deliberate, but quickly becomes 'automatic' as the respondent realizes there is no discernable pattern. It is impossible to 'game' the experiment. Even the most determined respondent quickly becomes defeated, and returns to virtual automatic responding.

Figure 1 shows an example of the vignette. The vignette shows a four-element combination, with the elements centered to make reading easy. There are no connectives. The ingoing assumption is that respondents will scan the vignette, graze for the necessary information, and assign their rating. The bottom of the vignette shows the actual rating scale, in this example a 9-point Likert scale, anchored at both ends. The design of the vignette makes it easy to go through a large number of different vignettes, without becoming fatigued. Furthermore, the program is set up so that as soon as the vignette is rated on the first scale (joining), the second rating scale comes up (select an emotion, Figure 2). After the respondent has rated the vignette on these two scales (joining, select an emotion), the program automatically presents the next vignette.

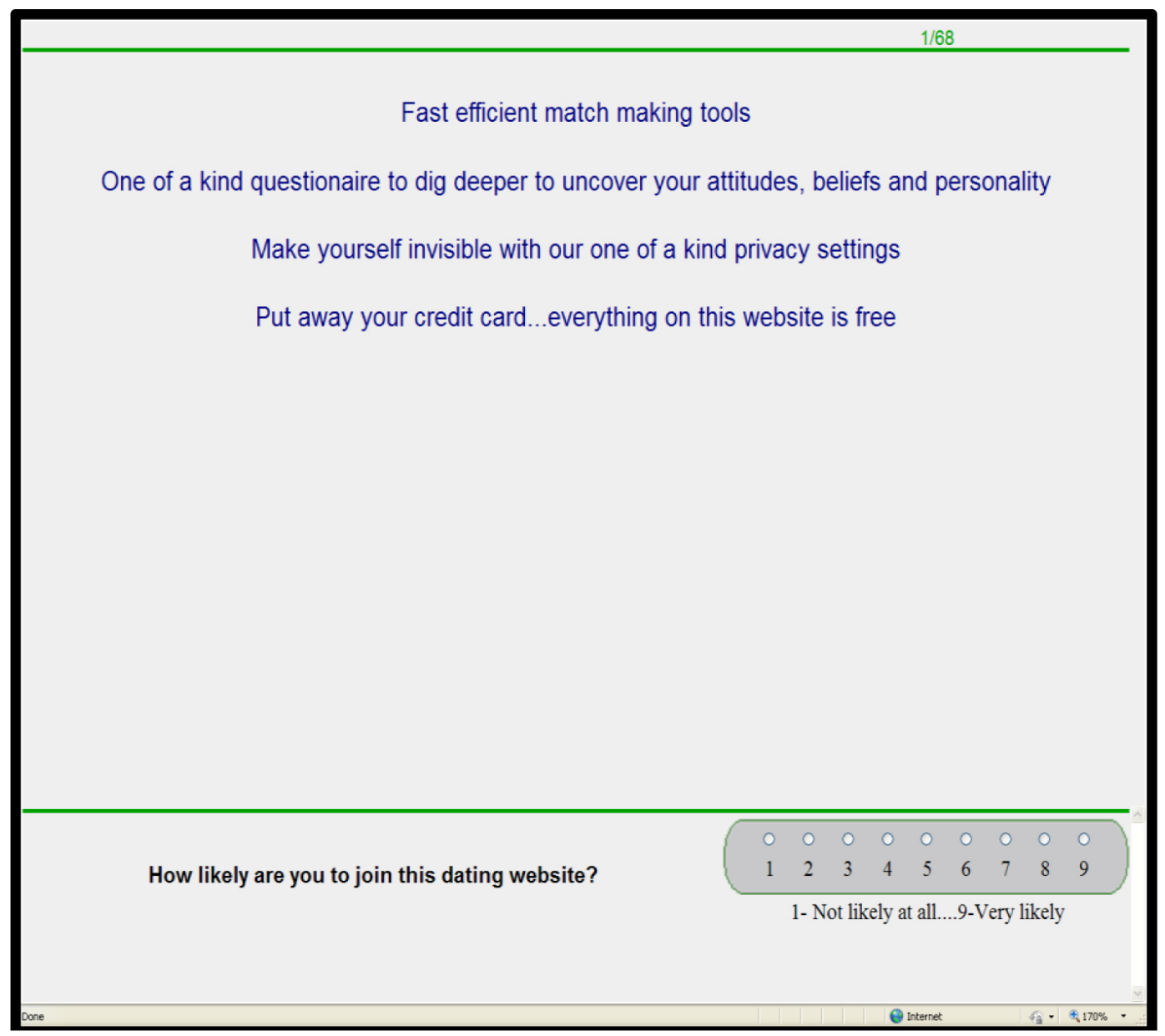

Figure 1. Example of a four-element vignette, with the first rating scale 


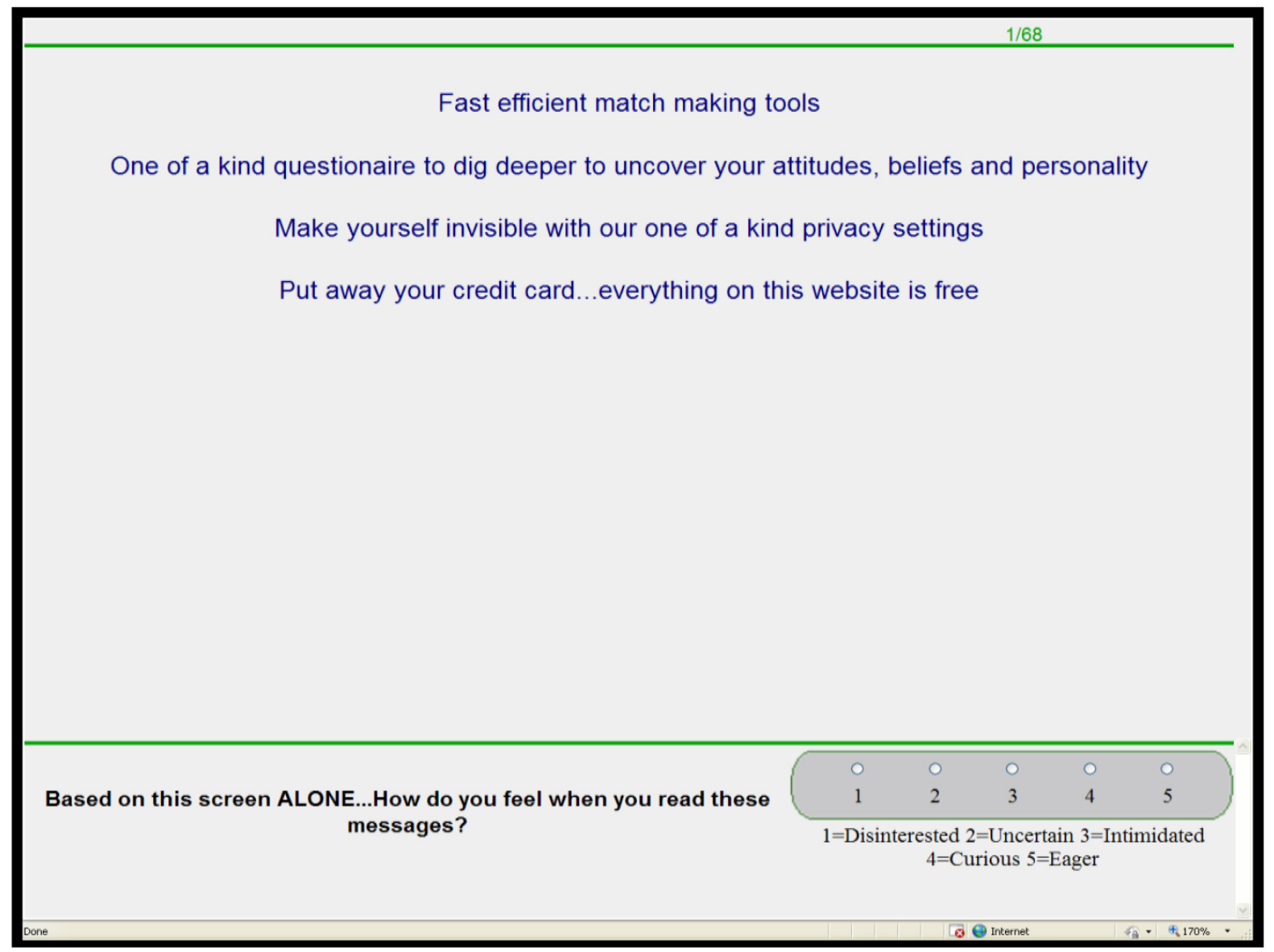

Figure 2. Example of the same four-element vignette, this time with instructions to select the appropriate emotion experienced after reading the vignette.

\section{Running The Study}

Upon clicking a link in the embedded email, sent by the e-panel provider, the respondent was presented with the invitation, and the information shown in Figure 3. The information provides very little background about the reasons for the study, other than the statement 'Today, you will taking a survey regarding Online Dating.' Although Mind Genomics is an experiment, the term 'survey' is less frightening, and was used in order to assuage any fears that might be aroused by the use of the technically more correct word 'experiment.'

There are some specific caveats about the actual material, such as the fact that all of the vignettes differ from each other. In the earlier visions of the program, especially those not on the web but done in person on micro-computers, many respondents stated that they felt they were seeing the same vignette several times. This is a natural reaction, stemming from the fact that the respondent sees the same elements, combined however into different vignettes. They remember some of the phrases, and when they see the phrase again, they may not realize that the other elements in the vignette have changed.

The second noteworthy piece of information is the statement that the study will take 10-15 minutes. Respondents do not like openended, boring experiences which seem that they will never end. By giving the respondent a sense of a 10-15-minute experience, we forestall a lot of the potential for the length of the Mind Genomics experiment to become an issue.

A parenthetic note: We should keep in mind that there were no marital requirements for this experiment when the respondents were selected. We could have limited the study to unmarried individuals, but we wanted to get a general representation of individuals, married, single, younger, older males and females, respectively.

\section{Data Analysis By Modeling - Question \# 1 - Join}

Each respondent evaluated a set of 48 vignettes, arranged according to an experimental design. The ratings for each respondent for question 1 (join the dating website) were transformed so that ratings of 1-6 were replaced by 0 to denote little or no interest, and ratings of $7-9$ were replaced by 100 to denote moderate or high interest. A very small random number was added to each binary transformation. The binary transformation follows the common practice of researchers in the social sciences and in political polling, who have come to realize that the precision of the scale is not easily translated to meaningfulness when the results of the study are subsequently applied by managers. Most managers, and indeed most researchers, do not know what the scale means, and especially have little or no idea what the intermediate scale points signify. The binary transformation simplifies the communication of the results and the use of the data. 
Table 2. Presents the summary results, sorted by the performance on Question \#1 (join)

\begin{tabular}{|c|c|c|c|c|c|c|c|}
\hline & & $\overrightarrow{\underline{\partial}}$ & $\frac{3}{\partial}$ & 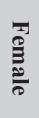 & $\begin{array}{l}\overrightarrow{\sigma o g} \\
\stackrel{\infty}{\infty} \\
\stackrel{\infty}{\infty}\end{array}$ & 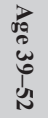 & \\
\hline & Base Size & 52 & 10 & 42 & 15 & 16 & 21 \\
\hline & Additive constant & 21 & 19 & 22 & 34 & 27 & 8 \\
\hline F6 & Put away your credit card...everything on this website is free & 14 & 17 & 13 & 10 & 18 & 13 \\
\hline F1 & Free personality test...matches you with more singles in your area & 13 & 20 & 11 & 6 & 12 & 17 \\
\hline B4 & Over 8,000 singles online now...making more connections everyday & 12 & 7 & 13 & 22 & 16 & \\
\hline A2 & Online dating made easy & 10 & 16 & 9 & 12 & 11 & 8 \\
\hline A6 & Receive matches by e-mail, free & 9 & 15 & 8 & 6 & 9 & 12 \\
\hline B3 & Over 1 million conversations per day, with 30,000 new singles everyday & 9 & 4 & 10 & 11 & 10 & 6 \\
\hline B1 & We are the best predictors of happy and long-lasting relationships & 8 & 1 & 9 & 12 & 11 & 2 \\
\hline $\mathrm{C} 2$ & $\begin{array}{l}\text { One-of-a-kind questionnaire to dig deeper to uncover your attitudes, beliefs and } \\
\text { personality }\end{array}$ & 8 & 8 & 8 & 10 & 8 & 6 \\
\hline B2 & $\begin{array}{l}\text { Has more dates, more relationships and more visits than any other online dating } \\
\text { website }\end{array}$ & 7 & 3 & 7 & -1 & 17 & 4 \\
\hline E4 & Partnership with Match.com to increase our services to you & 7 & 3 & 8 & -1 & 14 & 7 \\
\hline F4 & No credit card required & 7 & 6 & 8 & 2 & 12 & 8 \\
\hline B5 & $\begin{array}{l}\text { Debbie from New York says, "I never thought I would use a dating website... but that is } \\
\text { how I met my husband, Paul" }\end{array}$ & 6 & 6 & 6 & 12 & -4 & 10 \\
\hline D1 & Number one most trusted online dating website & 6 & -4 & 8 & 2 & 9 & 5 \\
\hline D5 & For singles concerned with privacy, rest assured contact details are never published & 6 & 7 & 5 & -7 & 4 & 16 \\
\hline E3 & Personal match maker working with you & 6 & 7 & 5 & 6 & -1 & 10 \\
\hline E5 & $\begin{array}{l}\text { No other website offers relationship expertise of someone like Dr. Phil or professional } \\
\text { match making services }\end{array}$ & 6 & 2 & 6 & 2 & 3 & 10 \\
\hline A4 & Registration is fast and effortless & 5 & 19 & 2 & 5 & 9 & 3 \\
\hline B6 & In the USA, 1 out of every couple found their spouse online & 4 & 11 & 3 & 7 & 9 & -1 \\
\hline $\mathrm{C} 4$ & A fun, unique way to meet people & 4 & 6 & 3 & 7 & 4 & 1 \\
\hline $\mathrm{A} 3$ & Meet singles all around the world & 3 & 11 & 2 & 4 & 2 & 4 \\
\hline A5 & Fast efficient match making tools & 3 & 18 & 0 & 5 & -2 & 5 \\
\hline $\mathrm{C} 1$ & Date smarter, not harder & 3 & 11 & 1 & 3 & 0 & 5 \\
\hline $\mathrm{C} 3$ & Find G-d's match for you & 3 & 2 & 3 & -7 & 5 & 9 \\
\hline C6 & Our online dating site and dating service is modern, professional and user-friendly & 2 & 8 & 1 & -4 & 5 & 4 \\
\hline D4 & Make yourself invisible with our one-of-a-kind privacy settings & 1 & -4 & 2 & -7 & 6 & 4 \\
\hline D6 & Ranked in 2011 as McAfee's most secure dating website & 1 & -1 & 2 & -7 & 5 & 4 \\
\hline $\mathrm{C} 5$ & Start finding all of the Mr. and Ms' Rights you can handle & -1 & 7 & -3 & -2 & -5 & 3 \\
\hline E1 & Oldest online dating website & -1 & 3 & -2 & -7 & 14 & -8 \\
\hline
\end{tabular}




\begin{tabular}{|c|c|c|c|c|c|c|c|}
\hline & & $\overrightarrow{\underline{\Xi}}$ & $\frac{3}{\partial}$ & 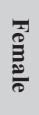 & $\begin{array}{l}\vec{D} \\
\stackrel{\infty}{\infty} \\
\stackrel{\infty}{\infty} \\
\stackrel{\infty}{\infty}\end{array}$ & 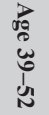 & $\begin{array}{l}\overrightarrow{8} \\
\text { of } \\
\text { Uू } \\
+ \\
+\end{array}$ \\
\hline A1 & Easy login... with Facebook & -2 & 15 & -6 & -16 & 4 & 3 \\
\hline $\mathrm{F} 2$ & Online dating for the cost of a single date & -2 & 6 & -4 & -13 & -6 & 9 \\
\hline F3 & Free trial for your first three months & -2 & 1 & -2 & -8 & -2 & 3 \\
\hline E2 & Use our respectable matching system & -3 & 3 & -4 & 1 & -10 & 0 \\
\hline E6 & Our website gives more meaning to 'we are family' than any other & -3 & 8 & -6 & -7 & -2 & -1 \\
\hline D2 & $100 \%$ invitation only...to better protect your privacy & -4 & -4 & -4 & -16 & 1 & 0 \\
\hline D3 & Your information is stored in our database for historical and legal purposes only & -7 & -7 & -7 & -20 & -1 & -2 \\
\hline F5 & Pay as you go...no contract necessary & -7 & -4 & -8 & -14 & -11 & 0 \\
\hline
\end{tabular}

Today, you will be taking a survey regarding Online Dating.

You will be seeing different screens of situations regarding Online Dating.

Although they may seem similar, each screen combination is unique.

You will be asked two questions for each screen description of combinations:

1) How likely are you to join this dating website based on this information?

$1=$ Not likely at all $\ldots . .9=$ Very Likely

2) Based on this screen ALONE... How do you feel when you read these messages?

1= Disinterested 2=Uncertain 3=Intimidated 4= Curious 5= Eager

You will be asked the SAME 2 questions for each screen. Please rate each screen combination as a single unit.

It will take you $10-15$ minutes to complete the study

You can track your progress on the top right of each screen.

Thank you for your participation in this important survey.

Please Click $>>$ to Continue.

$>$

Figure 3. The orientation page, shown to the respondent at the start of the Mind Genomics experiment

The first column is the element code, the second column is the element text, and the remaining columns are the results from the different groups (total, gender, age).

The base size - number of respondents in the specific group

Additive constant -percent of responses which would be 7-9 in the absence of elements. The additive constant is a purely estimated parameter since all the vignettes by design comprised 2-4 elements. Nonetheless, the additive constant can be viewed as a baseline, showing the predisposition of the respondent to be positive. The additive constants are low, with the younger respondents (age 18-38) most optimistic, and the older respondents (age 53+) least optimistic about the site.

The performance of the individual elements. Mind Genomics provides a rich database from which to extract patterns. Mind Genomics does not need a pattern to 'jump out,' with the elements of the pattern simply observations. Rather, each element is 'cognitively rich, with many possible meanings. The patterns which emerge come from both the meaning of the individual elements which score highest, as well as the commonality among those elements. 


\section{Total panel - free is the strongest performer:}

Put away your credit card...everything on this website is free

Free personality test... matches you with more singles in your area

\section{Male - many different elements, but free and easy are the strongest performers}

Free personality test... matches you with more singles in your area

Registration is fast and effortless

Fast efficient match making tools

Put away your credit card...everything on this website is free

Online dating made easy

Receive matches by e-mail, free

Easy login... with Facebook

Females - free, safe (with an emphasis on safe, no risk)

Put away your credit card...everything on this website is free

Over 8,000 singles online now...making more connections everyday

Age 18-38 - Others are involved

Over 8,000 singles online now...making more connections everyday

Age 39-52 - Free, others are involved, the system has a number of assurances of 'performance'

Put away your credit card...everything on this website is free

Has more dates, more relationships and more visits than any other online dating website

Over 8,000 singles online now...making more connections everyday

Partnership with Match.com to increase our services to you

\section{Age 53+ - Privacy, assurance of 'performance'}

Free personality test... matches you with more singles in your area

For singles concerned with privacy, rest assured contact details are never published

\section{Linking Emlinking Emotions To Elements}

An emerging topic of interest over the past decade has been the way emotions come into play when a person reads something or does something, the idea of affect as an accompanying feature of behavior. Often it is difficult to pinpoint the precise emotion, since there are hundreds of words which describe one or another feeling, emotion, disposition. The nomenclature of emotion makes it very difficult to select a set of words, although if a limited set is not chosen, the task becomes virtually impossible.

A parenthetical note: The same issue, description of the qualitative aspect of emotion, can be said to describe the state of our approach to the description of odor and a lesser issue but a problem nonetheless for the description of texture. The issue in emotion, olfaction, and texture, is simply the fact that there are no agreed-upon primaries, and the subjective richness of the emotion, the smell, and the touch can be simply overwhelming.
We recognized this problem, and selected five different emotions, two negative (uncertain, intimidated), one intermediate (disinterested), and two positive (curious, eager.) The emotions were not mean to describe a continuum, but simply designed to capture a variety of feelings, positive, negative, and a variety of actions (information-seeking; approach-avoidance.)

After the respondent rated the vignette on the overall evaluative criterion of 'join,' the respondent was instructed to rate how she or he felt when reading the vignette. The five selections became five new dependent variables. When a specific emotion or feeling was selected (e.g., uncertain) the newly created variable corresponding to that emotion was assigned the value of 100 . The remaining four newly created variables were assigned the rating of 0 .A small random number was added to each newly created rating.

The coefficients for the five newly created variables were estimated, this time again using OLS regression, but without an additive constant.

Table 3, 4 presents the linkages between the 36 elements and the nature of the feeling (both positives, neutral, both negatives, and then the four specific feelings).For the positive, disinterest (neutral) and negative feelings, we show the strongest linkages, shading those of 15 or higher. For the remaining four feelings (uncertain, intimidated, curious, eager) we shade those linkages of 11 or higher. A linkage of 10 is highly statistically significant in the OLS regression model

Table 3 tells us that the majority of strong emotional linkages to these elements are either disinterest or negative. Although there are some elements which may drive an individual to say that she or he will 'join' the dating site, there is very little 'massive' positive reaction. What positive reactions occur can be traced more to curiosity than to eagerness

\section{Discovering Mind-Sets In The Population}

Underlying the Mind Genomics effort is the belief that for any specific topic where decisions are made, people exhibit a range of criteria, or 'mind-sets.' The effort may be very broad such as what interests an individual in an organization, or very narrow, such as the topic of joining a data site, or even a narrower aspect of the topic, such as how to pay for the site, and so forth. The key is being able to ask questions, provide relevant answers, and execute the study among the relevant respondents. The topic of 'relevant' is an entirely separate issue, and may be limited to individuals who are single (for a data site), individuals who have used a dating site, or even individuals who have used a specific dating site. On the other hand, the relevant respondent may be just about anyone.

In the world of genomics, we deal with a gene, and alternative versions of the same gene, alleles. The comparison to Mind Genomics is metaphoric. Whether the respondents are from a specific group or from a general population, they nonetheless often divide into groups with different points of view, so-called mind-sets, mental genomes. The experiment we have just run in the above-discussed results provide us with the tools to isolate mental alleles, mental variations of the same 'gene, the gene being the ways one thinks about joining to a dating site. 
Table 3. Linkage between the 36 elements and the positive, neutral (disinterest) and negative feelings, as well as the four specific feelings

\begin{tabular}{|c|c|c|c|c|c|c|c|c|}
\hline & & \multicolumn{3}{|c|}{ General Feelings } & \multicolumn{4}{|c|}{ Specific Feelings } \\
\hline & & ¿ & 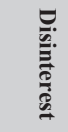 & 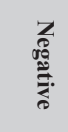 & 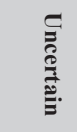 & 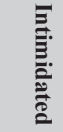 & פ & 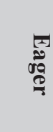 \\
\hline D4 & Make yourself invisible with our one-of-a-kind privacy settings & 16 & 2 & 8 & 8 & 8 & 6 & 2 \\
\hline $\mathrm{C} 3$ & Find G-d's match for you & 8 & 22 & -2 & 3 & 5 & -2 & 0 \\
\hline F5 & Pay as you go...no contract necessary & 9 & 16 & 2 & 6 & 3 & 3 & -1 \\
\hline F6 & Put away your credit card...everything on this website is free & -1 & 1 & 26 & -1 & 0 & 16 & 10 \\
\hline F1 & Free personality test...matches you with more singles in your area & 6 & 3 & 18 & 5 & 1 & 15 & 3 \\
\hline $\mathrm{C} 1$ & Date smarter, not harder & 7 & 2 & 18 & 7 & 0 & 15 & 3 \\
\hline C6 & Our online dating site and dating service is modern, professional and user-friendly & 5 & 4 & 17 & 6 & -1 & 17 & 0 \\
\hline $\mathrm{C} 2$ & One-of-a-kind questionnaire to dig deeper to uncover your attitudes, beliefs and personality & 10 & 2 & 17 & 7 & 3 & 14 & 3 \\
\hline A6 & Receive matches by e-mail, free & 7 & 6 & 15 & 7 & 0 & 14 & 1 \\
\hline $\mathrm{C} 4$ & A fun, unique way to meet people & 6 & 6 & 15 & 4 & 2 & 13 & 2 \\
\hline B6 & In the USA, 1 out of every couple found their spouse online & 13 & 8 & 6 & 9 & 4 & 5 & 1 \\
\hline B2 & Has more dates, more relationships and more visits than any other online dating website & 13 & 4 & 11 & 9 & 4 & 10 & 1 \\
\hline D5 & For singles concerned with privacy, rest assured contact details are never published & 13 & 4 & 9 & 6 & 7 & 6 & 3 \\
\hline F2 & Online dating for the cost of a single date & 12 & 13 & 2 & 10 & 2 & 3 & -1 \\
\hline D3 & Your information is stored in our database for historical and legal purposes only & 12 & 10 & 4 & 7 & 5 & 3 & 1 \\
\hline B4 & Over 8,000 singles online now...making more connections everyday & 12 & 4 & 12 & 11 & 1 & 8 & 4 \\
\hline B3 & Over 1 million conversations per day, with 30,000 new singles everyday & 12 & 4 & 10 & 7 & 5 & 10 & 0 \\
\hline D1 & Number one most trusted online dating website & 12 & 1 & 12 & 8 & 4 & 12 & 0 \\
\hline A1 & Easy $\operatorname{login} . .$. with Facebook & 11 & 8 & 7 & 9 & 2 & 3 & 4 \\
\hline D2 & $100 \%$ invitation only...to better protect your privacy & 11 & 8 & 6 & 5 & 6 & 5 & 1 \\
\hline A2 & Online dating made easy & 11 & 5 & 12 & 7 & 4 & 11 & 1 \\
\hline E1 & Oldest online dating website & 11 & 2 & 11 & 9 & 2 & 10 & 1 \\
\hline E2 & Use our respectable matching system & 10 & 5 & 8 & 6 & 4 & 7 & 1 \\
\hline E6 & Our website gives more meaning to 'we are family' than any other & 6 & 13 & 4 & 2 & 4 & 3 & 1 \\
\hline E4 & Partnership with Match.com to increase our services to you & 4 & 11 & 11 & 3 & 1 & 8 & 3 \\
\hline B1 & We are the best predictors of happy and long-lasting relationships & 6 & 10 & 11 & 5 & 1 & 11 & 0 \\
\hline $\mathrm{C} 5$ & Start finding all of the Mr. and Ms' Rights you can handle & 8 & 10 & 9 & 7 & 1 & 7 & 2 \\
\hline F4 & No credit card required & 4 & 9 & 14 & 4 & 0 & 8 & 6 \\
\hline A5 & Fast efficient match making tools & 8 & 6 & 14 & 7 & 1 & 10 & 4 \\
\hline E5 & $\begin{array}{l}\text { No other website offers relationship expertise of someone like Dr. Phil or professional match making } \\
\text { services }\end{array}$ & 3 & 6 & 14 & 0 & 3 & 10 & 4 \\
\hline B5 & $\begin{array}{l}\text { Debbie from New York says, "I never thought I would use a dating website... but that is how I met my } \\
\text { husband, Paul" }\end{array}$ & 9 & 6 & 13 & 7 & 2 & 12 & 1 \\
\hline D6 & Ranked in 2011 as McAfee's most secure dating website & 7 & 6 & 13 & 2 & 5 & 11 & 2 \\
\hline A3 & Meet singles all around the world & 8 & 7 & 12 & 5 & 3 & 9 & 3 \\
\hline F3 & Free trial for your first three months & 8 & 7 & 12 & 7 & 1 & 8 & 4 \\
\hline E3 & Personal match maker working with you & 6 & 6 & 12 & 3 & 3 & 9 & 3 \\
\hline A4 & Registration is fast and effortless & 9 & 9 & 9 & 7 & 2 & 7 & 2 \\
\hline
\end{tabular}


Howard Moskowitz (2019) Electronic Aids to Emotional Relations: A Mind Genomics Development Cartography of a ‘Dating App'

Table 4. Performance of the elements by the two mind-sets

\begin{tabular}{|c|c|c|c|}
\hline & & Mind-Set 1 & Mind-Set 2 \\
\hline & Base Size & 37 & 15 \\
\hline & Additive constant & 21 & 22 \\
\hline & Mind-Set 1: Lots of people, easy and free & & \\
\hline B4 & Over 8,000 singles online now...making more connections everyday & 18 & -3 \\
\hline F6 & Put away your credit card...everything on this website is free & 17 & 6 \\
\hline B3 & Over 1 million conversations per day, with 30,000 new singles everyday & 14 & -4 \\
\hline A6 & Receive matches by e-mail, free & 13 & -1 \\
\hline B1 & We are the best predictors of happy and long-lasting relationships & 13 & -5 \\
\hline $\mathrm{F} 1$ & Free personality test...matches you with more singles in your area & 13 & 12 \\
\hline B2 & Has more dates, more relationships and more visits than any other online dating website & 12 & -6 \\
\hline A2 & Online dating made easy & 11 & 6 \\
\hline A5 & Fast efficient match making tools & 10 & -15 \\
\hline A4 & Registration is fast and effortless & 9 & -3 \\
\hline F4 & No credit card required & 9 & 4 \\
\hline B5 & Debbie from New York says, "I never thought I would use a dating website... but that is how I met my husband, Paul" & 8 & 0 \\
\hline \multirow[t]{2}{*}{ E4 } & Partnership with Match.com to increase our services to you & 8 & 4 \\
\hline & Mind-Set 2 - Serious dater & & \\
\hline $\mathrm{C} 3$ & Find G-d's match for you & -5 & 22 \\
\hline D1 & Number one most trusted online dating website & 4 & 11 \\
\hline E3 & Personal match maker working with you & 4 & 11 \\
\hline $\mathrm{C} 2$ & One-of-a-kind questionnaire to dig deeper to uncover your attitudes, beliefs and personality & 6 & 10 \\
\hline \multirow[t]{2}{*}{ E5 } & No other website offers relationship expertise of someone like Dr.Phil or professional match making services & 4 & 8 \\
\hline & Does not drive a respondent to join & & \\
\hline E1 & Oldest online dating website & -4 & 7 \\
\hline $\mathrm{F} 2$ & Online dating for the cost of a single date & -4 & 4 \\
\hline D5 & For singles concerned with privacy, rest assured contact details are never published & 7 & 2 \\
\hline F3 & Free trial for your first three months & -3 & 2 \\
\hline C6 & Our online dating site and dating service is modern, professional and user-friendly & 3 & 1 \\
\hline E2 & Use our respectable matching system & -4 & 0 \\
\hline A3 & Meet singles all around the world & 6 & -3 \\
\hline $\mathrm{C} 1$ & Date smarter, not harder & 5 & -3 \\
\hline B6 & In the USA, 1 out of every couple found their spouse online & 7 & -4 \\
\hline $\mathrm{C} 4$ & A fun, unique way to meet people & 7 & -5 \\
\hline E6 & Our website gives more meaning to 'we are family' than any other & -2 & -5 \\
\hline F5 & Pay as you go...no contract necessary & -8 & -6 \\
\hline
\end{tabular}




\begin{tabular}{|c|c|c|c|}
\hline & & Mind-Set 1 & Mind-Set 2 \\
\hline D2 & $100 \%$ invitation only...to better protect your privacy & -3 & -7 \\
\hline D4 & Make yourself invisible with our one-of-a-kind privacy settings & 5 & -8 \\
\hline D6 & Ranked in 2011 as McAfee's most secure dating website & 6 & -9 \\
\hline D3 & Your information is stored in our database for historical and legal purposes only & -7 & -9 \\
\hline $\mathrm{C} 5$ & Start finding all of the Mr. and Ms' Rights you can handle & 2 & -10 \\
\hline A1 & Easy login... with Facebook & 6 & -22 \\
\hline
\end{tabular}

Discovering mind-sets in the population of respondents combines objective statistics and subjective interpretation. Each respondent generated a model relating the presence/absence of the elements to the binary value of $0 / 100$ ( 0 when the original rating was $1-6,100$ when the original rating was 7-9). The binary-transformed ratings were then used as the dependent variable and related to the presence/absence of elements. The coefficients (but not the additive constant) were used as inputs to a k-means clustering program (Jubes\& Jain, 1980). The program divided the respondents into two groups (clusters, mindsets), and then again into three groups. The criteria for dividing the respondents was mathematical in nature. The selection of the clusters, two or three, was based upon a simple pair of criteria, parsimony (fewer clusters are better than more clusters), and interpretability (the clusters must 'tell a coherent story.')

For these results, it was easy to interpret the two-cluster solution, suggesting two radically different mind-sets. Table 3 shows the coefficients for the two mind-sets. Both start with low additive constants, 21 and 22, respectively, suggesting that in the absence of the elements about one-fifth of the time the rating will be 7-9. This means that it is the task of the elements to drive 'join.' In neither mind-set are people ready to join.

The richness of the elements in terms of what they convey, how they represent the way a person feels, and the simplicity of the pattern reflects the nature of Mind Genomics. Rather than extracting a pattern from points, and thus forcing oneself to see order in possible chaos, Mind Genomics extracts a pattern from phrases which themselves are meaningful. One need not even 'name' the mind-sets to understand the results. Just knowing the high-scoring elements may often suffice, although it is in the nature of researchers to label groups, if only as a aide-memoire.

Mind-Set 1 responds to 'make it easy and free.'

Over 8,000 singles online now...making more connections everyday

Put away your credit card...everything on this website is free

Mind-Set 2 is a 'serious dater'

Find G-d's match for you

\section{Establishing The Consistency of The Ratings From Individual Respondents}

The question is often asked whether the respondents in these Mind Genomics studies are serious in their participation, or whether they just answer at random. As of this writing (Summer, 2019) the issue of survey fraud, especially with online studies, has come to the fore as a major topic, especially because survey fraud can be committed with 'bots' programmed to answer surveys as if the bots were legitimate respondents.

One way to determine whether or not the respondents were actually focused on doing the project uses a measure of 'goodness of fit' of the equation to the data, the multiple R-square. The individuallevel regression model, so-called curve-fitting model, OLS (ordinary least-squares) regression, may or may not 'fit the data. 'When the regression model fits the data, the R-squared is high. The R-square ranges from a high of 1.00 when the regression model fits the data perfectly, to a low of 0.0 when the regression model essentially fails entirely, and is simple a 'best fit' but is really irrelevant,

Figure 4 shows the distribution of R-square values for the respondents, each respondent generating a single value from the model generated by her or his ratings, versus the presence/absence of the elements. R-square values of 0.25 or higher $(\mathrm{R}>0.5)$ suggest that the respondent is taking the study seriously. Figure 4 shows that most respondents generate reasonably high R-square statistics for their individual models.

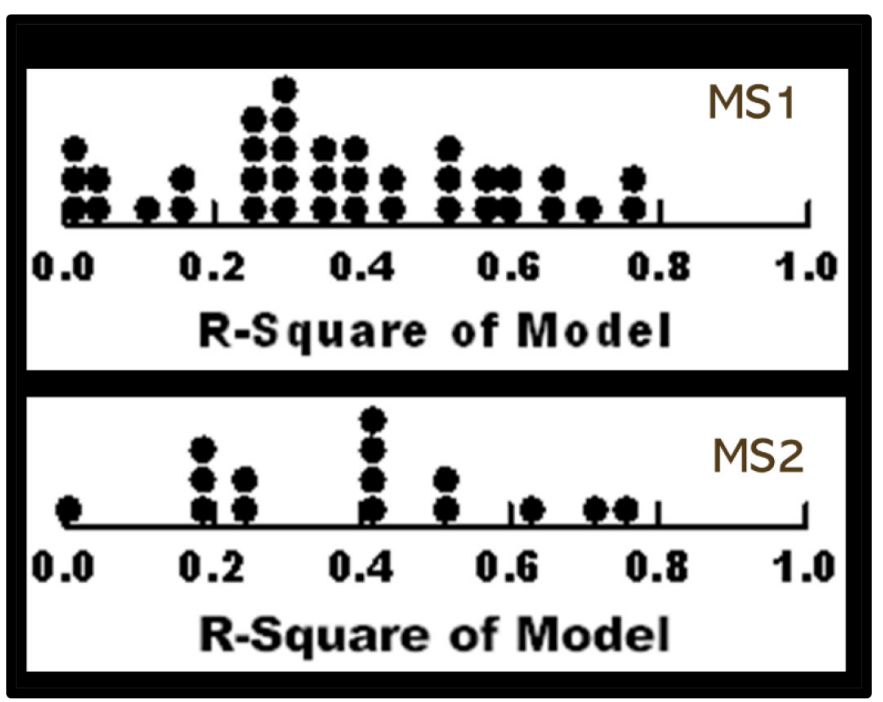

Figure 4. Distribution of R-square values by mind-set, for the individual models relating of question 1 ('Join') vs the presence/absence of the 36 elements 


\section{Finding Segments In The Population}

It is easy to classify people by who they ARE or what they DO. These classifications can be quickly obtained from many commercial sources. Once can also define a person by one of the many different classification schemes such as PRIZM ${ }^{\bullet}$ by Claritas, Inc. in San Diego, CA. What is almost impossible, however, is to identify the likely membership in a mind-set that is relevant to a specific, local issue such as dating. How can one assign a new person to Mind-Set 1 or MindSet 2 for a dating site?

Recent developments by author Gere have evolved into a method which assigns new individuals to the two mind-sets, using a simple algorithm. The approach, PVI (personal viewpoint identifier), is a simplified algorithm, taken in part from the more powerful method of discriminant function analysis [11] DFA requires the raw data, whereas the PVI uses the average data to identify a set of questions, which best differentiate among the different mind-sets. The PVI is a Monte-Carlo process, which adds 'noise' to the coefficients to simulate ordinary variation, and identifies the best set of questions and the pattern of answers. The output of the process is the set of questions (usually six), each with two answers, and thus 64 possible patterns of answers. The pattern of answers defines mind-set membership.

Figure 5 shows the PVI. Once the respondent participates in the PVI, the program automatically assigns the respondent to a mind-set, and stores the data. The PVI can be programmed to send feedback to the respondent based upon the pattern of responses, and the mind two which the participant in the PVI is assigned.

\begin{tabular}{|c|c|}
\hline euestion & Options \\
\hline EASY LOGIN_.. WITH FACEBOOK & I LOVE THIS SITE ALREADY \\
\hline FIND G-D'S MATCH FOR YOU & I LOVE THIS SITE ALREADY \\
\hline FAST EFFICIENT MATCH MAKING TOOLS & I DONT LIKE THIS ITE \\
\hline $\begin{array}{l}\text { OVER } 8,000 \text { SINGLES ONLINE NOW...MAKING MORE CONNECTIONS } \\
\text { EVERYDAY }\end{array}$ & O IDONT LIKE THIS SITE \\
\hline $\begin{array}{l}\text { WE ARE THE BEST PREDICTORS OF HAPPY AND LONG-LASTING } \\
\text { RELATION SHIPS }\end{array}$ & O I DONT LIKE THIS MITE \\
\hline $\begin{array}{l}\text { HAS MORE DATES, MORE RELATIONSHIPS AND MORE VISITS } \\
\text { THAN ANY OTHER ONLINE DATING WEBSITE }\end{array}$ & I DONT LIKE THIS ITE $\quad$ I LOVE THIS SITE ALREADY \\
\hline
\end{tabular}

Figure 5. The PVI (personal viewpoint identifier) for the dating site

\section{Discussion And Conclusions}

The sheer volume of interest in dating sites drive researchers to focus on the site as a way to understand the motives of people, their feelings, and their behavior. In turn, business people recognize the great deal of money to be made from these dating sites because those who are on the sites are there for emotional reasons, whether sincere or feigned, whether looking for connection or for something else.

Mind Genomics brings a different focus to the issue of dating sites. The sites are interesting as a product that can be designed, as well as a micro-topic of everyday life which is of great interest to people in the world of always-connected, and the ubiquitous Internet. The consequence of a new world of interconnections through technology, and increasing social isolation of people because of the advances in technology which have destroyed the tight-knit local communities, make a perfect matrix of research opportunities for Mind Genomics to look at various aspects of dating sites. This first study looks at the site as a business opportunity, using research questions and probes typically encountered in the development of products in the world of commerce. Further studies might well focus on issues of emotionality when the site is used. These further studies would represent the application of Mind Genomics to more traditional aspects of dating sites, the aspects looked at by sociologists and psychologists.

\section{Acknowledgement}

Attila Gere wishes to acknowledge and thank the Premium Postdoctoral Research Program of the Hungarian Academy of Sciences

\section{References}

1. Finkel EJ, Eastwick PW, Sprecher S (2012) Online Dating: A Critical Analysis from the Perspective of Psychological Science. Psychological science in the public interest

2. Blackhart GC, Fitzpatrick J, Williamson (2014) Dispositional factors predicting use of online dating sites and behaviors related to online dating. In: Computers in Human Behavior Elsevier.

3. Kim M, Kwon KN, Lee (2009) Psychological characteristics of Internet dating service users: The effect of self-esteem, involvement, and sociability on the use of Internet dating services. CyberPsychology\&Behavior 12: 445-449.

4. Sautter JM, Tippett RM, Morgan SP (2010) The social demography of Internet dating in the United States. Social Science Quarterly 91: 554-575.

5. Stevens SB, Morris TL (2007) College dating and social anxiety: Using the Internet as a means of connecting to others. CyberPsychology\&Behavior 10: 680-688.

6. Valkenburg PM, Peter J (2007) Who visits online dating sites? Exploring some characteristics of online daters. CyberPsychology\&Behavior 10: 849-852.

7. Moskowitz HR, Gofman A, Beckley J, Ashman H (2006) Founding a new science: Mind genomics. Journal of sensory studies 21: 266-307.

8. Moskowitz HR, Gofman A (2007) Selling blue elephants: How to make great products that people want before they even know they want them. Pearson Education.

9. Box GE, Hunter WG, Hunter JS (1978) Statistics for experimenters New York, John Wiley

10. Kahneman D, Egan P (2011) Thinking, fast and slow. New York: Farrar Straus and Giroux.

11. Crask MR, PerreaultJr WD (1977) Validation of discriminant analysis in marketing research. Journal of Marketing Research 14: 60-68.

\section{Citation:}

Konstantin Vuk Savicevich, Janna Kaminsky, Martin Braun, Attila Gere, Sharon Starke and Howard Moskowitz (2019) Electronic Aids to Emotional Relations: A Mind Genomics Development Cartography of a 'Dating App'. Ageing Sci Ment Health Stud Volume 3(4): 1-11. 